\title{
Effects of Losartan on Ventricular Remodeling in Experimental Infarction in Rats
}

\author{
Leonardo A M Zornoff, Luiz S Matsubara, Beatriz B. Matsubara, Sergio A R Paiva, Jod Spadaro
}

\author{
Botucatu, SP - Brazil
}

\begin{abstract}
Objective - To evaluate the effects of losartan on ventricular remodeling and on survival after myocardial infarction in rats.
\end{abstract}

Methods - After surgical occlusion of left coronary artery, 84 surviving male Wistar rats were divided into two groups: LO treated with losartan $(20 \mathrm{mg} / \mathrm{kg} /$ day, $n=33)$ and NT $(n=51)$, without medication. After 3 months, we analyzed mortality; ventricular to body mass ratio (VM/ $B M)$; myocardial hydroxyproline concentration (HOP); isovolumetric pressure, $+d p / d t,-d p / d t$, and diastolic volume/left ventricle mass ratio $(\mathrm{VO} / \mathrm{LV})$.

Results - Mortality was: $L O=22 \%$, and $N T=47 \%$ $(p<0.05)$. Ventricular mass, $(V M / B M, m g / g)$ was $4.14 \pm$ 0.76 and $3.54 \pm 0.48$, in the NT and LO groups, respectively $(p<0.05)$. HOP (median) was $4.92 \mathrm{vg} / \mathrm{mg}$ in the $L O$ and $5.54 \mathrm{vg} / \mathrm{g}$ in the NT group ( $p>0.05)$. The V0/LV values (median) were $0.24 \mathrm{~mL} / \mathrm{g}$ in group $L O$ and $0.31 \mathrm{~mL} / \mathrm{g}$ in group NT $(p<0.05)$ compared to NT group. There were no differences between the groups for $+d p / d t$ and $-d p / d t$ parameters.

Conclusion - 1- The use of losartan myocardial infarction causes an attenuation of ventricular remodeling, bringing about an increased survival, an attenuation of ventricular hypertrophy and dilation, and an improvement of the isovolumetric pressure; 2- the treatment does not modify the myocardial collagen concentration.

Key words: fibrosis, ventricular function, angiotensin II

Faculdade de Medicina de Botucatu - UNESP

Mailing address: Leonardo A. M. Zornoff - Depto de Clínica Médica - Faculdade de Medicina de Botucatu-UNESP - Rua Rubião Júnior, S/N - 18618-000 Botucatu, SP - Brazil
The alterations of ventricle architecture that may occur after acute myocardial infarction are known as ventricular remodeling ${ }^{1}$. Following the coronary occlusion, an acute ventricle dilation can be observed, characterized by thinning and distention of the infarcted region. This alteration is called an expansion of the infarction and is a result of the sliding of necrotic muscle groups, as a consequence of the disintegration of interfibrillar collagen. In the late phase, different degrees of cavitary dilation have been observed. This phenomenon is a result of the hypertrophy process involving both ventricles, and seems to occur as a response to an increase of parietal stress. In parallel, it has been shown that an abnormal accumulation of collagen (fibrosis) occurs in the viable regions of the myocardium, both in the ventricle with the infarction and in the right ventricle ${ }^{1}$.

The process of ventricular remodeling is associated in general with a worse prognosis, because its presence is related to a greater incidence of aneurysms, cardiac rupture, fibrosis, functional worsening, arrhythmia, and a greater mortality ${ }^{2}$. Different classes of drugs have been used as a strategy for the prevention or attenuation of ventricular remodeling. Over the last few years, the use of angiotensin-II $\mathrm{AT}_{1}$-receptor blockers has been increasingly well accepted for cardiovascular diseases treatment. However, the effects of this new class of drugs on the adaptation process following infarct are not yet completely clear.

So, the objective of this study was to analyze the effects of losartan, a selective angiotensin-II AT -receptor $_{1}$ blocker, on the variables of ventricular remodeling after acute myocardial infarction.

\section{Methods}

We used 238 male Wistar rats, weighing 200-250g, obtained from the UNESP Campus Botucatu animal facility.

An acute myocardial infarction was produced according to a previously described method ${ }^{3}$ that is already a standard procedure in our laboratory ${ }^{4}$. Brief ly, after etherinhaed anesthesia, a left thoracotomy was performed, between the $4^{\text {th }}$ and $5^{\text {th }}$ intercostal spaces. The heart was exte- 
riorized by lateral compression of the chest, and the left coronary artery ligated with a polyvinyl thread (5-0, Ethicon) at approximately $2 \mathrm{~mm}$ from its origin, between the rim of the left atrium and the pulmonary artery out flow. Then the heart was quickly replaced in the chest cavity, the chest closed, and the animals were kept in cages for recovery. The rats were fed with commercial food and had free access to water.

After 12 hours, corresponding to the period set by us for surgical recovery, the surviving animals $(n=84)$ constituted 2 groups: group NT $(n=51) \div$ formed by the animals with infarction who did not receive any medication; group LO $(n=33)$ formed by the animals with infarction who received, starting 12 hours after surgery, losartan $(20 \mathrm{mg} / \mathrm{kg} /$ day $)$ dissolved in drinking water, over a three-month period. Body weight and the mean volume of water intake by the animals were measured weekly to adjust the drug dilution in the drinking water and attain the desired dose.

After the division into groups, the animals were put under observation, and mortality in the two groups under study was recorded. After three months, the surviving animals (27 in group NT, 26 in group LO) were given intraperitoneal sodium pentobarbital $(50 \mathrm{mg} / \mathrm{kg}$ ) and heparin (1000 IU) and ventilated with positive pressure and $100 \%$ oxygen. Afterwards, the chest was opened, the carotids ligated, and the aorta catheterized with a \# 5 metal cannula, starting the retrograde myocardial perfusion with Krebs-Henseleit nutrient solution The following solution (in $\mathrm{mmol} / \mathrm{L}$ ) was used: $115 \mathrm{NaCl} ; 5.4 \mathrm{KCl} ; 1.2 \mathrm{MgSO}_{4} ; 1.5 \mathrm{CaCl}_{2} ; 1.15 \mathrm{NaH}_{2} \mathrm{PO}_{4} ; 25$ $\mathrm{NaHCO}_{3} ; 11$ glucose. (10UI/L) insulin and mannitol (8-mol/ L M) were added to this solution, to ensure better myocardial preservation ${ }^{5}$. Hearts were then removed from the chest and placed in a device for the study of isolated hearts, size 3 type 830 (Hugo Sachs Electronic - Germany), with a constant perfusion pressure of $75 \mathrm{mmHg}$. The nutrient solution was continuously oxygenated with a $95 \% \mathrm{O}_{2}$ and $5 \% \mathrm{CO}_{2}$ gas mixture, keeping the partial oxygen pressure between 500 and $600 \mathrm{mmHg}$, temperature at $37^{\circ} \mathrm{C}$, $\mathrm{pH}$ between 7.3 and 7.4. The left atrium was opened and the apex of the left ventricle punctured with a needle, to drain the ventricular cavity, preventing the accumulation of fluid inside it. A latex balloon tied to a $\mathrm{PE} 90$ polyethylene tube was placed in the ventricle cavity. The other extremity of the polyethylene tube was connected to a three-way stop cock, one of which was coupled to a pressure transductor (Statham P23 XL) and the other one to a 1-mL syringe that allowed a variation in the volume of the intracavitary balloon. The right atrial musculature, comprising the sinoatrial nodule, was extirpated and the electrode of an artificial pacemaker placed in the right ventricle myocardium, to maintain artificially a heart rate between 240 and $250 \mathrm{bpm}$.

By means of the preparation described above, Starling curves were obtained with fluid infusion into the balloon, which allowed variation of the diastolic pressure of the left ventricle from 0 to $30 \mathrm{mmHg}$ through gradual increments of $5 \mathrm{mmHg}$, whereby the systolic pressure corresponding to each volume variation was recorded. In such preparations, in which the heart operates in isovolumetric contractions, systolic pressure is accepted as an indication of contractility. The maximal rate of rise of left ventricular pressure $(+\mathrm{dp} /$ $\mathrm{dt})$ and the maximal rate of decrease of left ventricular pressure (-dp/dt) were also recorded. These indexes were used respectively as parameters of the left ventricle systolic and diastolic function. The calibration factor of the left ventricle derivative was obtained according to the technique used by Moura Campos ${ }^{6}$.

After the functional study, the hearts were removed from the perfusion device, dried with filter paper, and then dissected. The right and left ventricles (including the interventricular septum) were weighed and prepared for morphometric analysis. The heart weight, as adjusted to the rat's body weight ratio (VM/BM), was used for the estimate of the degree of ventricular hypertrophy. The ventricular volume corresponding to a diastolic pressure equal to zero was called V0 and reflected the ventricular volume when the preload was theoretically null. The rate between $\mathrm{V} 0$ and the left ventricle weight ratio $(\mathrm{V} 0 / \mathrm{LV},(\mathrm{mL} / \mathrm{g})$ was used as a parameter of ventricular dilation.

The hearts were fixed in a $10 \%$ formaldehyde for marphometric study. Measurements were performed in section 5 to $6 \mathrm{~mm}$ from the apex to the base because this section reflected the mean value of the section results of the whole ventricle $^{7,8}$. The myocardial tissue obtained was stained with hematoxylin-eosin (HE) and used for morphometric analysis, carried out by measuring the epicardial and endocardial lengths of the segments with and without infarction, using an image analyser software (SigmaScan (Jandel Scientific, California, USA). In this way, the percentage of the length of the infarction region with regard to the total length of the left ventricle was obtained.

The degree of myocardial fibrosis was quantified by hydroxyproline dosage in the right ventricle, according to the technique described by Switzer ${ }^{9}$. The remodeling process occurs in the whole heart, so that the volume overload, as well as hormone stimuli such as the activation of the renin-angiotensin-aldosterone and adrenergic systems, operates in a uniform manner in both ventricles. The presence of a large scar region, a result of the myocardial infarction, makes the hydroxyproline quantification of the left ventricle become an inadequate index for the measurement of myocardial remodeling, because fibrosis is diffuse all over the entire left ventricle. We therefore resorted to the measurement of hydroxyproline in the right ventricle as an index of interstitial fibrosis, in response to a local or systemic humoral stimulus secondary to acute myocardial infarction.

In the statistical study, we used survival analysis (Kaplan Meyer curve) for mortality; the differences between curves were analyzed by the Log-Rank test and by the COX regression model. For the systolic function (SP and +dp/dt) and (-dp/ $\mathrm{dt}$ ) and cardiac hypertrophy (VM/BM) we used the Student's $t$ test. For the diastolic function (-dp/dt), fibrosis (HOP), and ventricular dilation ( V0/LV), we used the Mann-Whitney test. The level of significance used was $5 \%$. 


\section{Results}

Data on mortality are presented in figure 1 . Within the three-months observation period, mortality in the studied groups was $22 \%$ for the animals in group LO and $47 \%$ for the animals in group NT. The risk ratio between the two groups was $2.008(\mathrm{p}<0.05)$.

Figure 2 shows the results of the functional study, using systolic pressure as a contractility indicator. We can see that systolic pressure in group LO was statistically greater than the pressures obtained in group NT $(\mathrm{p}<0.05)$. With regard to +dp/dt, we can see that the animals in group LO had a performance that was not statistically different from that of the animals in group NT (fig. 3). Similar results were observed with regard to -dp/dt (fig. 4).

Table I shows the morphometric results of the animals of groups LO and NT. Regarding the estimate of cardiac hypertrophy, we found a smaller $\mathrm{VM} / \mathrm{BM}$ ratio in animals treated with losartan $(3.54 \pm 0.48 \mathrm{mg} / \mathrm{g})$ as compared with that in untreated animals $(4.14 \pm 0.76 \mathrm{mg} / \mathrm{g})$.

For the HOP concentrations showed no significant differences between.

The data on intensity of ventricular dilation showed that the animals in group LO had a lower $\mathrm{V} 0 / \mathrm{LV}$ ratio than the animals in group NT.

Concerning infarct size, the animals treated with losartan had an infarct size $(39.5 \pm 6.2 \%)$ that was not statistically different from that of the untreated animals $(36.65 \pm 7.8 \%)$.

\section{Discussion}

The results of this investigation stressed the beneficial effect of losartan use on several variables of ventricular remodeling in rats, after myocardial infarction.

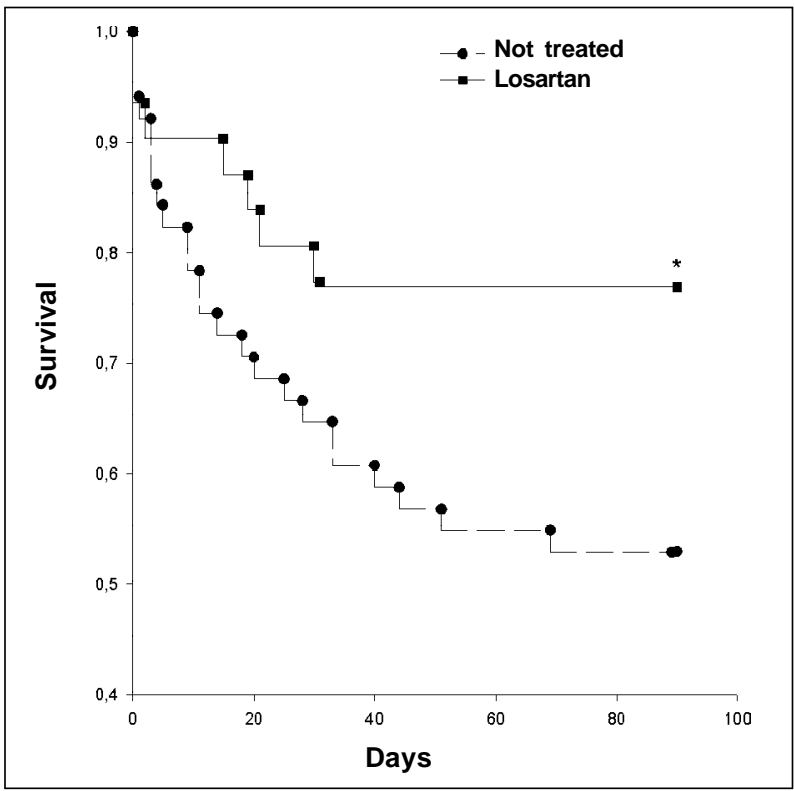

Fig. 1 - Effect of losartan treatment on the percentage of survival of rats with infarction. Kaplan-Meyer analysis followed by Cox-Mantel's log-rank test. $* \mathrm{p}<0.05$.
Limited information is available about angiotensin-II $\mathrm{AT}_{1}$-receptors' action on mortality, after experimental acute myocardial infarction. Thus, Richer-Giudicelli et al. ${ }^{10}$ proved that irbesartan administration increased the survival of rats with myocardial infarction in a dose-dependent manner. Milavetz et al. ${ }^{11}$ using the same model found that the administration of losartan had the same impact on mortality as captopril. Hu et al. ${ }^{12}$, on the other hand, found no evidence of a protective effect of losartan on the mortality of rats, after eight weeks of treatment following experimental infarction.

In our study, the result of losartan administration was an evident reduction in mortality. The risk ratio, which defines the probability of death between the study groups, showed that the probability of dying of an untreated animal was $100 \%$ greater than that of a treated animal.

The estimation of cardiac hypertrophy, by ventricular weight and body weight ratio is used in several experimental models. After coronary occlusion, an inflammatory process sets in on the infarction region, and afterwards a fibrous scar replaces this region. In the right ventricle and in the regions without infarction of the left ventricle, myocyte growth and collagen clumping occur. So the increase in ventricular mass does not reflect exclusively the hypertrophy process. Despite these limitations, the VM/BM rate is accepted in the literature as a parameter of cell growth in this model ${ }^{13-16}$. In our study, losartan administration attenuated the degree of adaptive post myocardial infarction hypertrophy, as compared with no treatment. Other authors have identified a decrease in of the hypertrophy process after infarction, with angiotensin-II $\mathrm{AT}_{1}$-receptors, ${ }^{14,15}$, results that support our findings. In our research, we cannot disregard the possibility of hypertrophy attenuation being also influenced by the decrease of the afterload in response to the hypotensive effect of losartan.

One of the main characteristics of ventricular remodeling after acute myocardial infarction is the presence of ventricular dilation. During the acute phase, this process is a result of infarct expansion whereas the late ventricular dilation of the left ventricle is a consequence eccentric type of ventricular hypertrophy.

Our results show that, as compared with the untreated animals, the treated animals had smaller ventricular volumes, as normalized for mass. This fact indicates that the treatment with losartan atenuates of the ventricular dilation after the ischemic insult.

With regard to the estimate of myocardial fibrosis, we used the concentration of HOP in the right ventricle a. Although it is an indirect method, HOP concentraton is accepted as a index of collagen quantity ${ }^{17,18}$. Milanez et al. ${ }^{19}$, working with infarction in rats treated with captopril, observed that the hydroxyproline concentration in the right ventricle and in a noninfarcted region of the left ventricle showed a linear and positive correlation with the size of the infarct. In this model, the finding of infarcts affecting the whole free wall of the left ventricle is not rare. Thus, a risk exists that parts of the necrotic area will influence the 


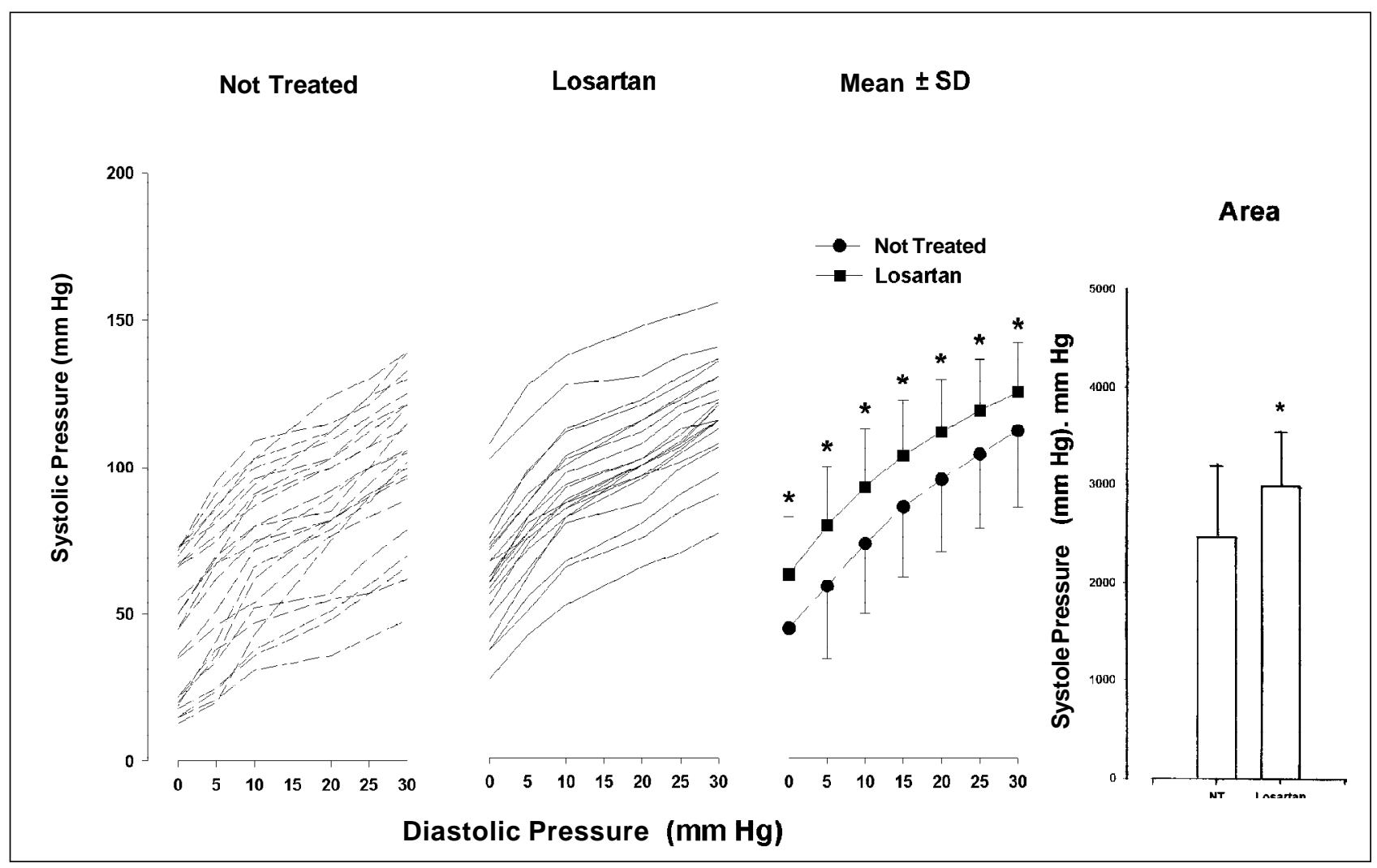

Fig. 2 - Graphic representation, of the individual curves and of the means \pm standard deviations, of the rate between isovolumetric systolic pressure and diastolic pressure in the groups of untreated rats and of losartan $(20 \mathrm{mg} / \mathrm{kg} /$ day $)$-treated rats with infarction. ${ }^{*} \mathrm{p}<0.05$.

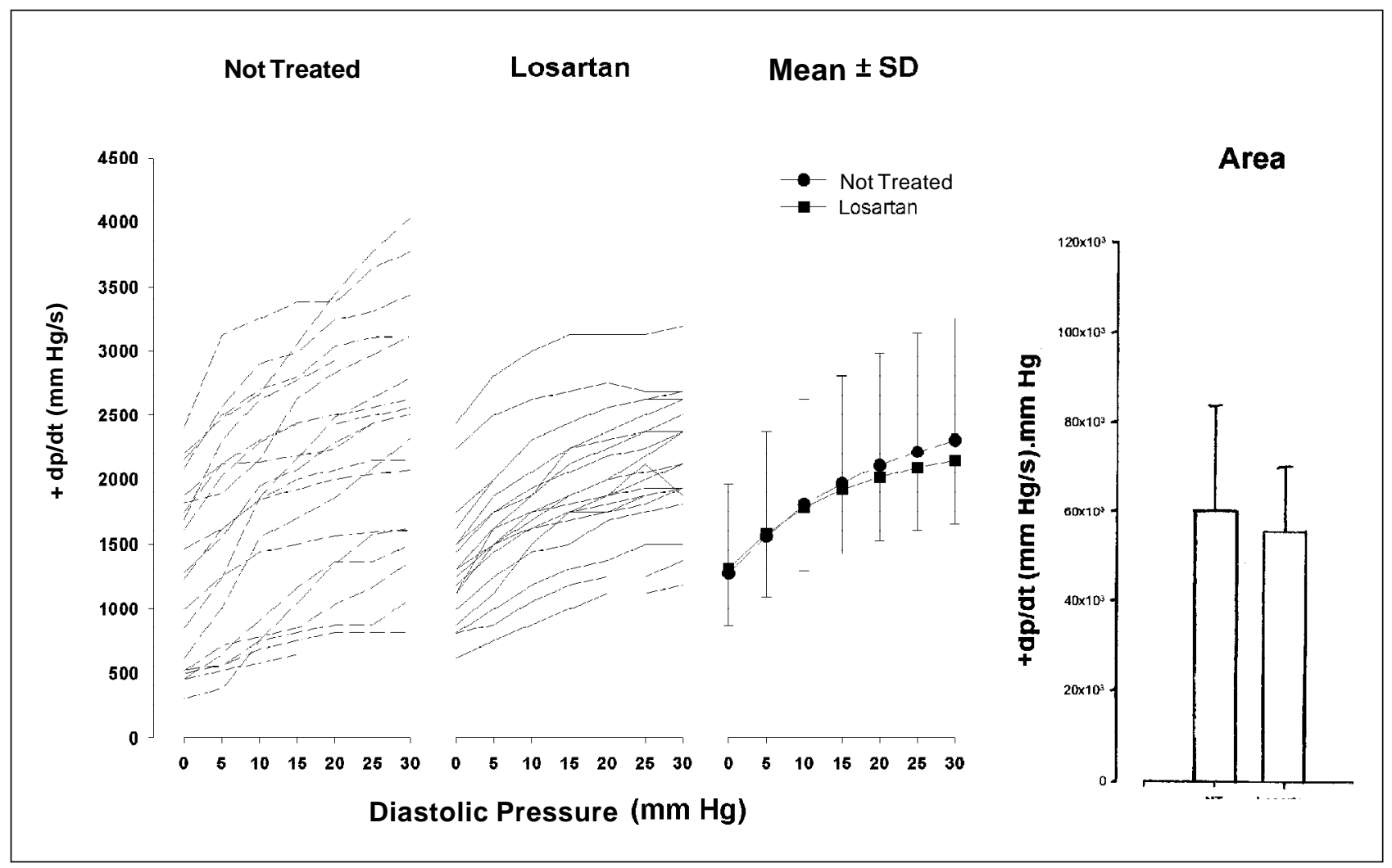

Fig. 3 - Graphic representation, of the individual curves and of the means \pm standard deviations, of the rate between $+\mathrm{dp} / \mathrm{dt}$ and the diastolic pressure of untreated and losartan $(20 \mathrm{mg} / \mathrm{kg} / \mathrm{day})$-treated rats with infarction. 


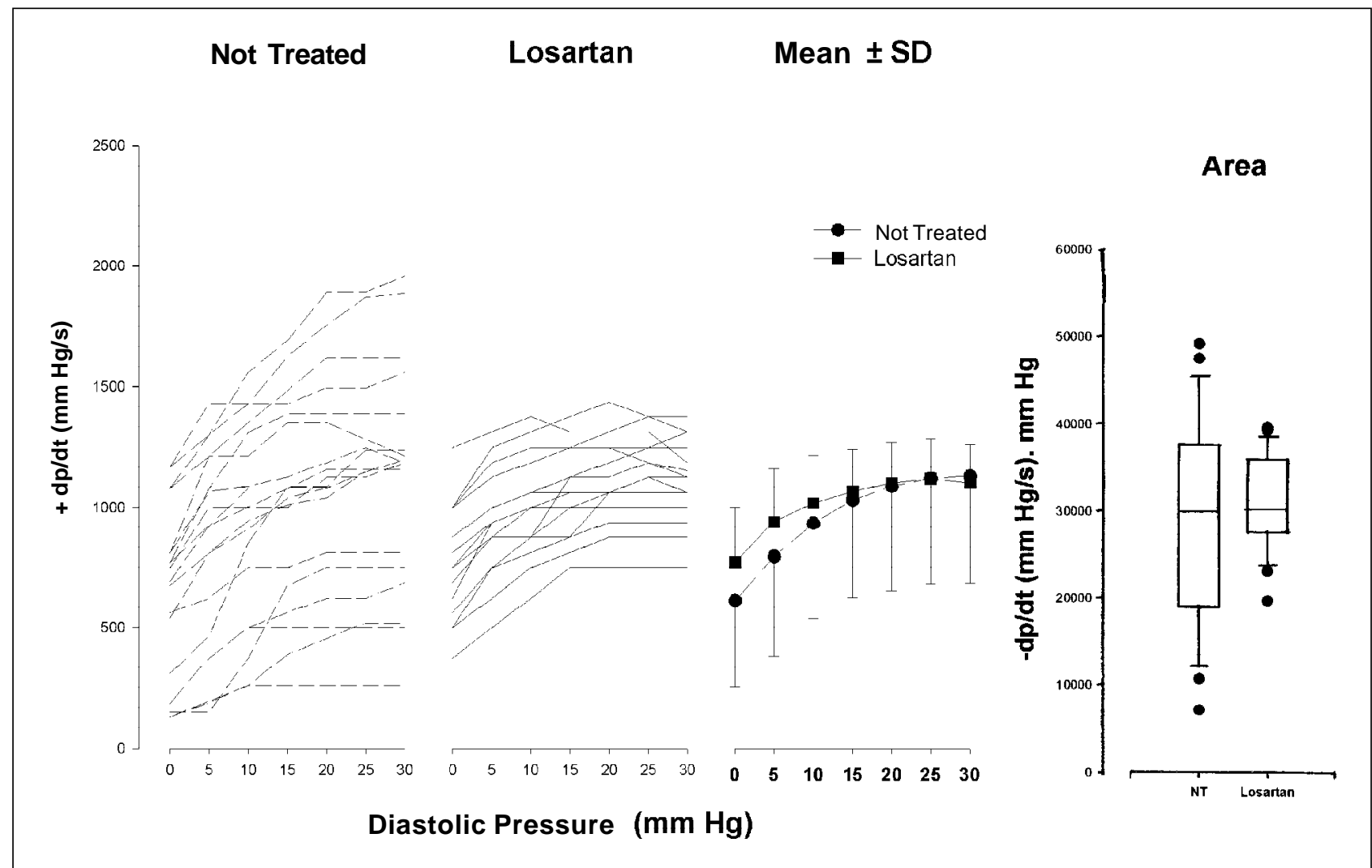

Fig. 4 - Graphic representation, of the individual curves and of the means + standard deviations, of the rate between -dp/dt and the diastolic pressure of untreated and losartan (20mg/ $\mathrm{kg}$ /day)-treated rats with infarction.

\begin{tabular}{|c|c|c|}
\hline \multicolumn{3}{|c|}{$\begin{array}{l}\text { Table I - Morphometric data in the groups of untreated rats (NT) } \\
\text { and of rats treated with losartan } 20 \mathrm{mg} / \mathrm{kg} / \mathrm{day}(\mathrm{LO})\end{array}$} \\
\hline \multirow[t]{2}{*}{ Variable } & \multicolumn{2}{|c|}{ Group } \\
\hline & NT & LO \\
\hline VM/BM (mg/g) & $4,14 \pm 0,76$ & $3,54 \pm 0,48 *$ \\
\hline $\mathrm{V} 0 / \mathrm{LV}(\mathrm{ml} / \mathrm{g})$ & $0,31(0,29-0,36)$ & $0,24(0,20-0,34)^{*}$ \\
\hline HOP (mg/g) & $5,54(3,34-7,49)$ & $4,92(4,19-5,79)$ \\
\hline Infarct size (\%) & $36,65 \pm 7,8$ & $39,5 \pm 6,2$ \\
\hline \multicolumn{3}{|c|}{$\begin{array}{l}\mathrm{VM} / \mathrm{BM} \text { - ratio between heart mass and body mass of the rat; V0/LV-ratio } \\
\text { between the ventricular volume corresponding to a diastolic pressure } \\
\text { equal to zero and the weight of the left ventricle; HOP- hydroxyproline } \\
\text { concentration in the right ventricle; VM/BM and infarct size - mean } \\
\text { values } \pm \text { standard deviation. V0/LV and HOP - median values, with } 25 \% \\
\text { and } 75 \% \text { percentiles. } * \mathrm{p}<0.05 \mathrm{vs} \mathrm{NT} \text {. }\end{array}$} \\
\hline
\end{tabular}

dosages performed in the noninfarcted region. Therefore, in our study, we decided not to consider the left ventricle HOP dosages.

Despite all evidence that fibroblast activity is regulated by A-II and by aldosterone ${ }^{20}$, the capacity of the A-II $\mathrm{AT}_{1}$-receptors to interfere in the fibrosis process is still controversial. Some authors ${ }^{21,22}$ have found a decrease in tissue fibrosis with this class of drugs whereas others have found no evidence of treatment interfering with the intensity of fibrosis in different experimental models ${ }^{15,23}$.

In our study, we found no differences in HOP concentration between the two groups. So our results suggest that, in this model, losartan does not interfere with the amount of collagen.

As for the functional study, our data were not uniform. The rats treated with losartan had better performance compared with the untreated animals, when systolic pressure was considered as an index. No significant differences, however, occurred regarding $+\mathrm{dp} / \mathrm{dt}$ and $-\mathrm{dp} / \mathrm{dt}$. Our data agree with previous studies, where the interference capacity

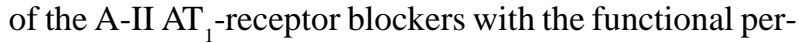
formance depended on the variable used ${ }^{11,24,25}$.

All together, our results allow us to draw the following conclusions: 1) the use of losartan after acute myocardial infarction is accompanied by a change in ventricular remodeling, with an increase in survival, an attenuation of cardiac hypertrophy and of ventricular dilation. Treatment does not interfere with the amount of collagen measured in the right ventricle; 2) the capacity of losartan to interfere with ventricular function depends on the parameter used, with relevance only concerning the isovolumetric systolic pressure.

\section{Acknowledgements}

ToMrs. Valéria Maria Ricarelli de Oliveira for her collaboration. 


\section{References}

1. Pfeffer MA, Braunwald E. Ventricular remodeling after myocardial infarction: experimental observations and clinical implications. Circulation 1990; 81: 116172.

2. Pfeffer MA, Braunwald E. Ventricular enlargement following infarction is a modifiable process. Am J Cardiol 1991; 68: 127D-31D.

3. Maclean D, Fishbein MC, Maroko PR, Braunwald E. Hyalunonidase-induced reduction in myocardial infarct size. Science 1976; 194: 199-200.

4. Spadaro J, Hashimoto LM, Franco RSS, Bregagnollo EA, Tucci PJF. Efeito da administração prévia de amiodarona na incidência precoce de fibrilação ventricular durante isquemia miocárdica experimental. Arq Bras Cardiol 1984; 42: 25-9.

5. Zornoff LAM, Paiva SAR, Tornero MTT, Carvalho MSS, Tucci PJF. Influência do acréscimo de manitol à solução nutriente no desempenho mecânico e no grau de edema miocárdico de corações isolados de ratos. Arq Bras Cardiol 1995; 64: 225-9.

6. Moura Campos $\mathrm{CF}^{\circ}$. A contração isovolumétrica do ventrículo esquerdo na estenose aórtica. Tese - Escola Paulista de Medicina - São Paulo, 1968.

7. Spadaro J, Fishbein MC, Hare C, Pfeffer MA, Maroko PR. Characterization of myocardial infarcts in the rat. Arch Pathol Lab Med 1980; 104: 179-83.

8. Oh B-H, Ono S, Rockman HR, Ross J Jr. Myocardial hypertrophy in the ischemic zone induced by exercise in rats after coronary reperfusion. Circulation 1993; 87: 598-607.

9. Switzer BR. Determination of hydroxiproline in tissue. J Nutr Biochem 1991; 2: 229-31.

10. Richer-Giudicelli C, Fornes P, Cazaubon C, Nisato D, Giudicelli JF. Effects of angiotensin II AT1 receptor blockade on survival, systemic and coronary hemodynamics and cardiac remodeling in postischemic heart failure in rats. Circulation 1997; 96(suppl): 3605

11. Milavetz JJ, Raya TE, Johnson CS, Morkin E, Goldman S. Survival after myocardial infarction in rats: captopril versus losartan. J Am Coll Cardiol 1996; 27 : 714-9.

12. Hu K, Gaudron $\mathrm{P}$, Anders H-J, et al. Chronic effects of early started angiotensin converting enzyme inhibition and angiotensin AT1-receptor subtype blockade in rats with myocardial infarction: role of bradykinin. Cardiovasc Res 1998; 39 : 401-12.

13. Raya TE, Fonken SJ, Lee RW, et al. Hemodynamic effects of direct angiotensin II blockade compared to converting enzyme inhibition in rat model of heart failure. Am J Hypertens 1991; 4: 3345-405.
14. Schiefer B, Wirger A, Meybrunn M, et al. Comparative effects of chronic angiotensin-converting enzyme inhibition and angiotensin II type 1 receptor blockade on cardiac remodeling after myocardial infarction in the rat. Circulation 1994; 89: 2273-82.

15. Taylor K, Patten RD, Smith JJ, et al. Divergent effects of angiotensin-converting enzyme inhibition and angiotensin II-receptor antagonism on myocardial cellular proliferation on collagen disposition after myocardial infarction in rats. J Cardiovasc Pharmacol 1998; 31: 654-60.

16. Pfeffer MA, Pfeffer JM, Fishbein MC, et al. Myocardial infarct size and ventricular function in rats. Circ Res 1979;44: 503-12.

17. Mill JG, Milanez MC, Busatto VC, Moraes AC, Gomes MG. Ativação da enzima conversora de angiotensina no coração após infarto do miocárdio e suas repercussões no remodelamento ventricular. Arq Bras Cardiol 1997; 69: 101-10.

18. Litwin SE, Litwin CM, Raya TE, Warner AL, Goldman S. Contractility and stiffnes of noninfarcted myocardium after coronary ligation in rats. Effects of chronic angiotensin-converting enzyme inhibition. Circulation 1991; 83: 1018-37.

19. Milanez MC, Gomez MGS, Vassalo DV, Mill JG. Effects of captopril on intersticial collagen in the myocardium after infarction in rats. J Card Fail 1997; 3: 18997.

20. Brilla CG, Zhou G, Matsubara L, Weber KT. Collagen metabolism in cultured adult rat cardiac fibroblasts: response to angiotensin II and aldosterone. J Mol Cell Cardiol 1994; 26: 809-20.

21. Frimm CC, Sun Y, Weber KT. Angiotensin II receptor blockade and myocardial fibrosis of the infarcted rat heart. J Lab Clin Med 1997; 129: 439-46.

22. Thai HM, Van HT, Gaballa MA, Goldman S, Raya TE. Effects of AT1 receptorblockade after myocardial infarct on myocardial fibrosis, stiffnes, and contractility. Am J Physiol 1999; 276: H873-80.

23. Kanda T, Araki T, Nakano M, et al. Chronic effects of losartan in a murine model of dilated cardiomyopathy: comparison with captopril. J Pharmacol Exp Ther 1995; 273: 955-8

24. Yoshiyama M, Takeuchi K, Amura T, et al. Effects of candesartan and cilazapril on rats with myocardial infarction assessed by echocardiography. Hypertension 1999; 33: 961-8.

25. Ambrose J, Pribnow DG, Giraud GD, Perkins KD, Muldoon L, Greenberg BH Angiotensin type 1 receptor antagonism with irbersartan inhibits ventricular hypertrophy and improves diastolic function in the remodeling post-myocardial infarction ventricle. J Cardiovasc Pharmacol 1999; 33: 433-9. 